\title{
Synthesis of Ordered Pt Nanocube Arrays Directed by Block Copolymer Nanotemplate and Their potential on Ethanol Oxidation Reaction
}

\author{
Zhi-da Wang, $, * 1, \S$ Yuan Gan, ${ }^{1,2, \S}$ Yi-lang Mai, ${ }^{1,2}$ Yan Shi, ${ }^{1}$ Shuo Cao,${ }^{3}$ Zhuo-xin Lu, ${ }^{1}$ Chang- \\ qing Guo, ${ }^{1}$ Hongyi-Tan, ${ }^{1}$ Chang-feng Yan ${ }^{*, 1,2}$
}

\begin{abstract}
${ }^{1}$ CAS Key Laboratory of Renewable Energy, Guangdong Key Laboratory of New and Renewable Energy Research and Development, Guangzhou Institute of Energy Conversion, Chinese Academy of Sciences, Guangzhou, China, 510640 .

${ }^{2}$ University of Chinese Academy of Sciences, Beijing, China, 100039.

${ }^{3}$ Institute of Metal Research, Chinese Academy of Sciences, Shenyang, China, 110016.

*Corresponding to: C.-F. Yan (yancf@ms.giec.ac.cn); Z.-D. Wang (wangzd@ms.giec.ac.cn)
\end{abstract}

\section{EXPERIMENTAL DETAILS}

\subsection{Preparation of BC nanopattern and grid-like nanotemplate}

Diblock copolymer of polystryrene-block-poly(4-vinylpyridine) [PS(41500)-b-P4VP(17500), $\mathrm{PDI}=1.15$, purchased from Polymer Source Inc. Quebec, Canada] was dissolved in $20 \mathrm{ml}$ dry tetrahydrofuran (THF) with a VP concentration of $5.1 \mathrm{mM} \cdot \mathrm{L}^{-1}$ to form spherical micelles consisted of the P4VP core and the PS corona. Carbon paper $(20 \times 10 \times 0.21 \mathrm{~mm}, \mathrm{HCP} 120$, purchased from Hesen Co. Ltd.) cleaned with a stream of nitrogen was selected as the supporting substrate, on which $0.4 \mathrm{~mL}$ of the copolymer solution was spin-coated (KW-4A spin-coater, purchased from Institute of Microelectronics of Chinese Academy of Sciences) at $4000 \mathrm{rpm}$ for $1 \mathrm{~min}$. The coated specimens were dried in air for $24 \mathrm{~h}$ to form ordered $\mathrm{BC}$ nanopatterns, and were then treated in an air plasma cleaner (110W, YZD08-2C, Tonson Tech.) for $100 \mathrm{~s}$ to obtain the grid-like nanotemplates.

\subsection{Synthesis of Pt NPs}

Metal precursor $\mathrm{H}_{2} \mathrm{PtCl}_{6} \cdot 6 \mathrm{H}_{2} \mathrm{O}$ (purchased from Shanghai Chemical Reagent Co.) was dissolved with a $\mathrm{Pt}$ concentration of $0.1 \mathrm{~g} \cdot \mathrm{mL}^{-1}$ in deionized water. Then the $\mathrm{HCl}$ was added as capping agent with $\mathrm{HCl} / \mathrm{H}_{2} \mathrm{PtCl}_{6}$ mass ratio of 0 (without $\mathrm{HCl}$ ), $0.1,0.18,0.25$ and 0.32 , respectively. The as-prepared grid-like nanotemplates was spin-coated (4000 rpm, $1 \mathrm{~min})$ with $0.4 \mathrm{~mL}$ of the $\mathrm{HCl} / \mathrm{H}_{2} \mathrm{PtCl}_{6}$ solution to encapsulate both the precursor and the capping agent, followed by a 20 minite plasma cleaning to remove the organic templates and reduce the Pt precursors, after which 
uniform and ordered Pt NP arrays supported on carbon paper were obtained.

For the preparation of multiplied Pt-polyhedron arrays, the as-prepared specimen was subjected to multiple routes consisted of identical BC-synthesized processes. The conditions of every process (including grid-like nanotemplate preparation, $\mathrm{HCl} / \mathrm{H}_{2} \mathrm{PtCl}_{6}$ encapsulation and plasma-cleaning steps) were as same as those described above.

\subsection{Pt NP Characterizations}

Scanning electron microscope (SEM) was conducted with an S-4800 instrument at $2.0 \mathrm{kV}$ for the surface morphology observation. X-ray diffraction (XRD) data was obtained on a PAN alytical X'Pert diffractometer (X'Pert PRO MPD, PW3040/60) with $\mathrm{Cu}-\mathrm{K} \alpha(\lambda=0.154060 \mathrm{~nm})$ radiation $(40 \mathrm{kV}, 40 \mathrm{~mA})$ to determine the phase composition of the Pt polyhedrons. X-ray fluorescence (XRF) data were obtained on an AXIOSmAX-PETRO instrument with a reference sample of $5 \mu \mathrm{g}$ Ir to calculate the Pt loading. To eliminate the Ir effects on the following characterizations of catalytic performance, half of each specimen $(10 \times 10 \mathrm{~mm})$ was used in XRF measurements. Transmission electron microscopy (TEM) was carried out on a JEM-2100 microscope to determine the morphology and crystal shape of the fresh catalyst. The point resolution was $0.23 \mathrm{~nm}$ and the accelerating voltage was $200 \mathrm{kV}$

\subsection{Electrochemical catalysis of Pt NPs}

Hydrogen adsorption and desorption were characterized on a tri-electrode electrochemical system (CHI600E, CH instruments), with Pt NP coated carbon paper (half for CV test and half for XRF measurements) as the working electrode, a saturated mercury/mercurous sulfate electrode $\left(\mathrm{Hg} / \mathrm{Hg}_{2} \mathrm{SO}_{4},-0.7 \mathrm{~V}\right.$ vs. $\left.\mathrm{RHE}\right)$ as the reference electrode, a Pt wafer as the counter electrode, and the $\mathrm{N}_{2}$-saturated $0.5 \mathrm{M} \mathrm{H}_{2} \mathrm{SO}_{4}$ solution as the electrolyte. $\mathrm{CV}$ method was carried out on the electrochemical system within a scanning range of -0.65 to $0.6 \mathrm{~V}$ (vs. $\mathrm{Hg} / \mathrm{Hg}_{2} \mathrm{SO}_{4}$, namely, a range of 0.05 to $1.3 \mathrm{~V}$ vs. RHE) to determine the H-desorption peaks of the Pt polyhedrons. The scanning rate is $50 \mathrm{mV} \cdot \mathrm{s}^{-1}$.

EOR performance was evaluated on the mentioned tri-electrode electrochemical system with the same working electrode and reference electrode, except for $\mathrm{Ag} / \mathrm{AgCl}$ as counter electrode. $\mathrm{N}_{2}$ saturated $1 \mathrm{M} \mathrm{KOH}+1 \mathrm{M} \mathrm{CH}_{3} \mathrm{CH}_{2} \mathrm{OH}$ solution was used as the electrolyte. $\mathrm{CV}$ method was carried out at a scanning rate of $50 \mathrm{mV} \cdot \mathrm{s}^{-1}$ within -0.8 to $0.3 \mathrm{~V}(-0.6$ to $0.5 \mathrm{~V}$ vs. RHE) to investigate the corresponding oxidation current densities. 


\section{SUPPORTING FIGURES FOR EXPERIMEAL PART}

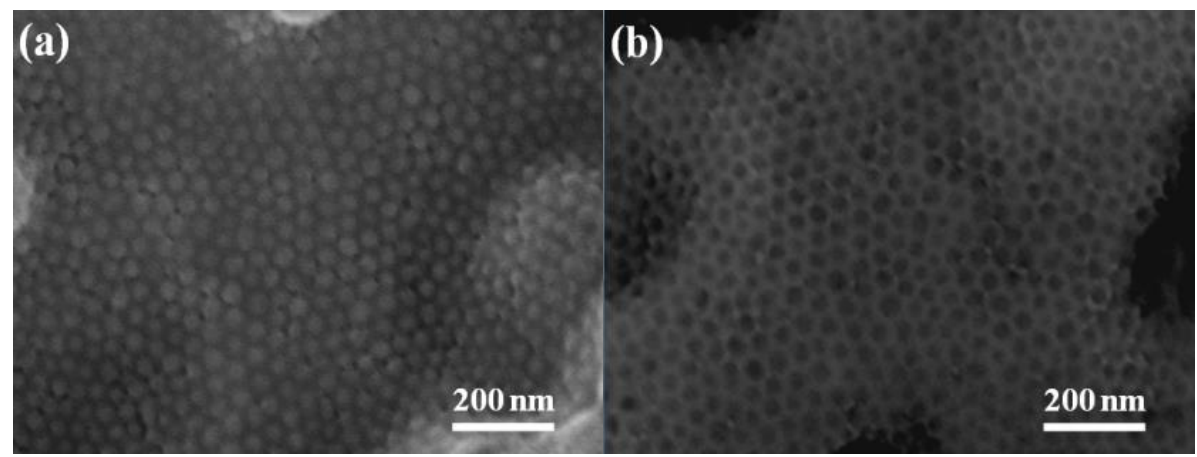

Figure S1. (a) SEM image of the BC nanopattern on carbon paper. (b) Grid-like nanotemplate.
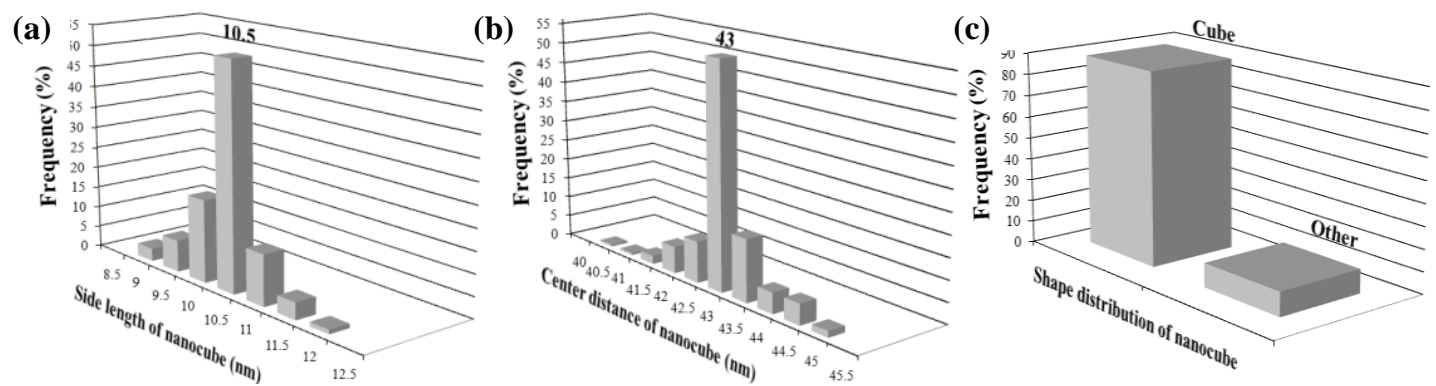

Figure S2. Statistic results of the Pt NC arrays in Figure 1D. (a) Particle size. (b) Spacing. (c) Shape distribution.

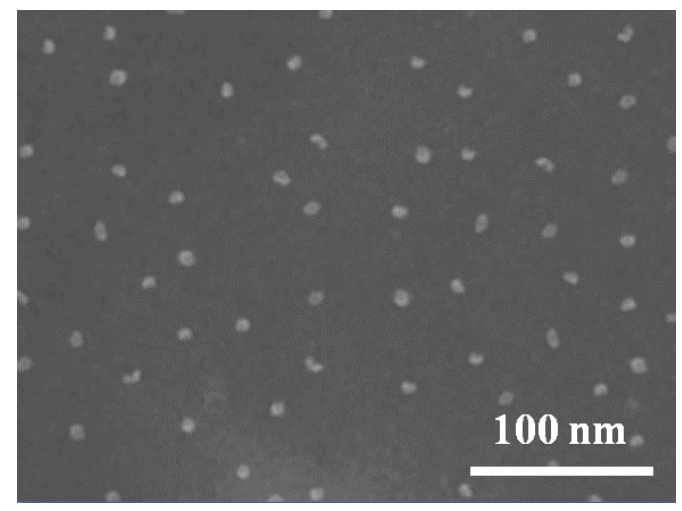

Figure S3. SEM image of the Pt NPs with an $\mathrm{HCl}$ content of $32 \%$ in $\mathrm{HCl} / \mathrm{H}_{2} \mathrm{PtCl}_{6}$ precursor.

\section{COMPUTATIONAL PART}

\subsection{Computation method}

The Vienna ab initio simulation package code (VASP) was used to conducted DFT calculation. The exchange and correlation energy was taken into account by Perdew-Burke-Ernzerhof (PBE) functional. ${ }^{1}$ The projector augmented wave (PAW) potentials was used to consider electron-core interaction. ${ }^{2}$ The energy cutoff of plane-wave basis was set to $400 \mathrm{eV}$. Methfessel-Paxton smearing was set to $0.1 \mathrm{eV}^{3}$ The corresponding k-point samplings were denser than $0.3 \AA^{-1}$.Crystal facets: (100), (110), (111), (211), (311), were taken into consideration, in which (100), (110), (111) are low- 
index planes and (211), (311) are planes containing the $\{111\}$ steps and the $\{100\}$ terraces. To ensure convergence, all the Pt surface models were built with 5-9 layers depending on the degree of openness. During optimization, the topmost 2-4 layers were relaxed, while the remaining layers were fixed. The vacuum region between the periodically repeated slabs was $12 \AA$, and the dipole correction was employed to correct potential spurious terms arising from the asymmetry of the slabs. ${ }^{4}$ VASP sol model was used to calculate solvent effect of gas phase molecules.

\subsection{Calculation process}

In this work, we firstly calculated the surface energy of each crystal plane of Pt NPs affected by hydrogen halides, and then substituted the Pt facets and their corresponding surface energies into the Wulff model to construct the Pt NPs and study their morphological transition. The HCl-absorbed model refers to Li and coworkers's work, in which the energy of Pt crystal surface was defined as: ${ }^{5}$

$$
\gamma_{S}=\frac{1}{2 A}\left(E_{S}^{\text {unrelax }}-N E_{b}\right)+\frac{1}{A}\left(E_{S}^{\text {relax }}-E_{S}^{\text {unrelax }}\right)
$$

where $A$ is the surface area, $E_{S}^{\text {relax }}$ and $E_{S}^{\text {unrelax }}$ are the energies of the relaxed and unrelaxed surfaces, respectively. $N$ is the number of atoms in the slab and $E_{b}$ is the bulk energy per atom. The surface energy of different facets on Pt without adsorption can be calculated according to eq. 1, as listed in Table S1.

Table S1. Surface energy of different facets on Pt without adsorption

\begin{tabular}{cl}
\hline Crystal facet & $\gamma_{s}\left(\mathrm{~J} / \mathrm{m}^{2}\right)$ \\
\hline $\operatorname{Pt}(100)$ & 1.87 \\
$\operatorname{Pt}(110)$ & 1.93 \\
$\operatorname{Pt}(111)$ & 1.67 \\
$\operatorname{Pt}(211)$ & 1.70 \\
$\operatorname{Pt}(311)$ & 1.81 \\
\hline
\end{tabular}

The adsorption energy of $\mathrm{HCl}, B E_{H C l}$, is given by:

$$
B E_{H C l}=\left(E_{s-H C l}-E_{s}-E_{H C l}^{S O l v}\right)
$$


In eq. $2, E_{S-H C l}$ is the energy of $\mathrm{HCl}$-covered surface, $E_{s}$ is the surface energy without adsorption and $E_{H C l}^{\text {Solv }}$ is the energy of $\mathrm{HCl}$ in solution, respectively. The surface energy of $\mathrm{HCl}$-covered Pt NP above $0 \mathrm{~K}$ is described as: ${ }^{5}$

$$
\gamma_{H C l}=\gamma_{S}+\frac{1}{A}\left(B E_{H C l}+Z P V E_{P t-H C l}-n\left[-T S_{H C l}\left(T, c^{0}\right)+Z P V E_{H C l}+R T \ln \frac{c}{c^{0}}\right]\right)
$$

here, $Z P V E_{P t-H C l}$ and $Z P V E_{H C l}$ are the calculate zero point vibrational energies, $n$ is the number of adsorbed $\mathrm{HCl}$ molecules, $S_{H C l}\left(T, c^{0}\right)$ is the entropy of the system, $R$ is the gas constant, $T$ is set as $298 \mathrm{~K}, c$ is the concentration of $\mathrm{HCl}$, and $c^{0}$ equals $1 \mathrm{M}$. With eq. 3 , the HCl-covered Pt surface energy can be calculated.

Then at low $\mathrm{HCl}$ concentrations, $\mathrm{Cl}$-covered phase becomes the dominant factor. According to eq. 2, the adsorption energy of $\mathrm{Cl}$ is defined as:

$$
B E_{C l}=\left[E_{s-C l}-E_{s}-\left(E_{H C l}^{\text {solv }}-E_{H}^{\text {solv }}\right)\right]
$$

where $E_{H}^{\text {solv }}$ is the $\mathrm{H}$ energy considering the solvent effect.

Similarly, the Cl-covered model can be written as

$\gamma_{C l}=\gamma_{S}+\frac{1}{A}\left(B E_{C l}+Z P V E_{P t-C l}-n\left[-T S_{C l}\left(T, c^{0}\right)+Z P V E_{H C l}+R T \ln \frac{c}{c^{0}}\right]\right)$

Finally, With eq. 3 and eq. 5, the $\mathrm{HCl}$-covered Pt surface energy at high $\mathrm{HCl}$ content and $\mathrm{Cl}$-covered Pt surface energy at low $\mathrm{HCl}$ content can be calculated

\subsection{Calculation results}

As reported by Gossenberger and coworkers, ${ }^{6}$ the adsorbate coverage changes with the change of $\mathrm{HCl}$ concentration. The $\mathrm{Cl}$-covered phase was stable at low content, whereas the $\mathrm{HCl}$-covered phase was stable at high concentration regions. The adsorption model with the $\mathrm{HCl}$ coverage at high and low content are shown in Figure S4 and Figure S5, in which $\theta$ is the coverage and the color is blue for $\mathrm{Pt}$, green for $\mathrm{Cl}$, and white for $\mathrm{H}$, respectively. The corresponding adsorption energy of $\mathrm{HCl}$ on Pt crystal plane are listed in Table S1 and Table S2 ( $B E_{H C l}$ means the unit area energy). 


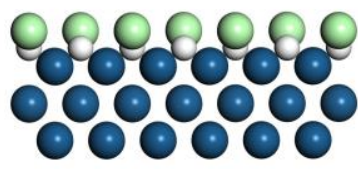

(100), $\theta=0.50$

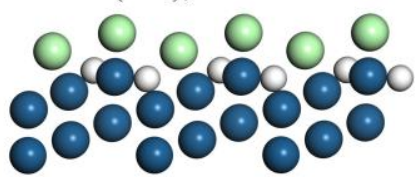

(211), $\theta=0.67$

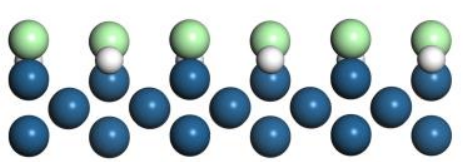

(110), $\theta=0.50$

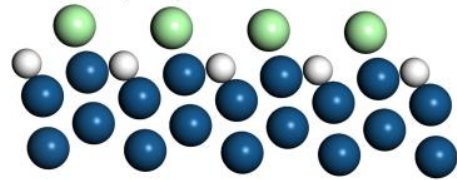

(311), $\theta=0.33$

\section{○.89898:8 00000000 00000000}

(111), $\theta=0.50$

Figure S4. Adsorption model for the Pt planes with high $\mathrm{HCl}$ coverage at higher $\mathrm{HCl}$ content.

Table S2. The corresponding adsorption energy of $\mathrm{HCl}$ on Pt crystal facets at higher content.

\begin{tabular}{cccc}
\hline Crystal facet & $\theta$ & $B E_{H C l}(\mathrm{eV})$ & $B E_{H C l} / A\left(J / \mathrm{m}^{-2}\right)$ \\
\hline $\operatorname{Pt}(100)$ & 0.50 & -2.20 & -1.12 \\
$\operatorname{Pt}(110)$ & 0.50 & -2.20 & -0.79 \\
$\operatorname{Pt}(111)$ & 0.50 & -0.96 & -0.56 \\
$\operatorname{Pt}(211)$ & 0.67 & -0.13 & -0.11 \\
$\operatorname{Pt}(311)$ & 0.33 & -1.17 & -0.73 \\
\hline
\end{tabular}

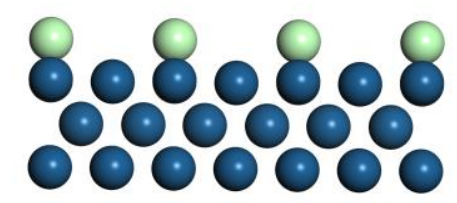

(100), $\theta=0.17$

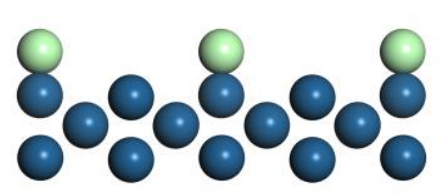

(110), $\theta=0.25$

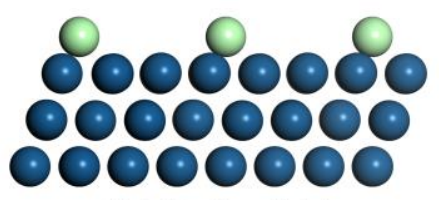

(111), $\theta=0.11$

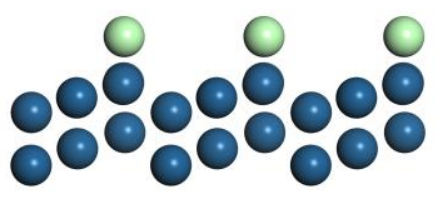

(211), $\theta=0.17$

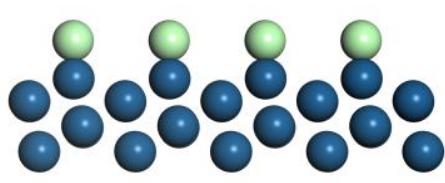

(311), $\theta=0.25$

Figure S5. Adsorption model for the $\mathrm{Pt}$ planes with low $\mathrm{HCl}$ coverage at lower $\mathrm{HCl}$ content.

The adsorption energies of $\mathrm{HCl}$ in Table $\mathrm{S} 3$ are positive because the energy of the $\mathrm{Cl}$ energy used here is the D-value of $\mathrm{HCl}$ minusing $\mathrm{H}$, representing that only $\mathrm{Cl}$ are adsorbed on the $\mathrm{Pt}$ planes. Because the energy of $\mathrm{HCl}$ is lower than the total energy of $\mathrm{H}$ and $\mathrm{O}$ atoms due to their binding energy, the calculated adsorption energy shifts to the positive range. Finally, based on Li and coworkers' work and the calculations above, the adsorption energy at different $\mathrm{HCl}$ contents of $0 \%$, 
$10 \%$ and $25 \%$ are calculated and the results show a morphological transition from quasi-sphere to nanocube, as shown in the Figure 3.

Table S3. The adsorption energy of $\mathrm{HCl}$ on Pt crystal planes at lower content.

\begin{tabular}{cccc}
\hline Crystal facet & $\theta$ & $B E_{H C l}(\mathrm{eV})$ & $B E_{H C l} / A\left(J / \mathrm{m}^{-2}\right)$ \\
\hline $\operatorname{Pt}(100)$ & 0.17 & 1.56 & 0.53 \\
$\operatorname{Pt}(110)$ & 0.25 & 1.46 & 0.53 \\
$\operatorname{Pt}(111)$ & 0.11 & 1.94 & 0.51 \\
$\operatorname{Pt}(211)$ & 0.17 & 1.85 & 0.79 \\
$\operatorname{Pt}(311)$ & 0.25 & 1.40 & 0.86 \\
\hline
\end{tabular}

References:

(1) Perdew, J. P.; Burke, K.; Ernzerhof, M. Phys Rev Lett 1996, 77, 3865.

(2) Kresse, G.; Joubert, D. Phys Rev B 1999, 59, 1758.

(3) Methfessel, M.; Paxton, A. T. Phys Rev B 1989, 40, 3616.

(4) Neugebauer, J.; Scheffler, M. Phys Rev B 1992, 46, 16067.

(5) Li, Q.; Rellan-Pineiro, M.; Almora-Barrios, N.; Garcia-Rates, M.; Remediakis, I. N.; Lopez, N. Nanoscale 2017, 9, 13089.

(6) Gossenberger, F.; Roman, T.; Gross, A. Electrochim Acta 2016, 216, 152. 